\title{
Corrigendum: Genotyping with CRISPR-Cas-derived RNA-guided endonucleases
}

Jong Min Kim, Daesik Kim, Seokjoong Kim \& Jin-Soo Kim

Nature Communications 5:3157 doi: 10.1038/ncomms4157 (2014); Published 20 Jan 2014; Updated 6 Feb 2015

This Article contains an error in Fig. 3. The labels 'T7E1' and 'RGEN-RFLP' appear on the wrong gels. The correct version of this figure appears below.
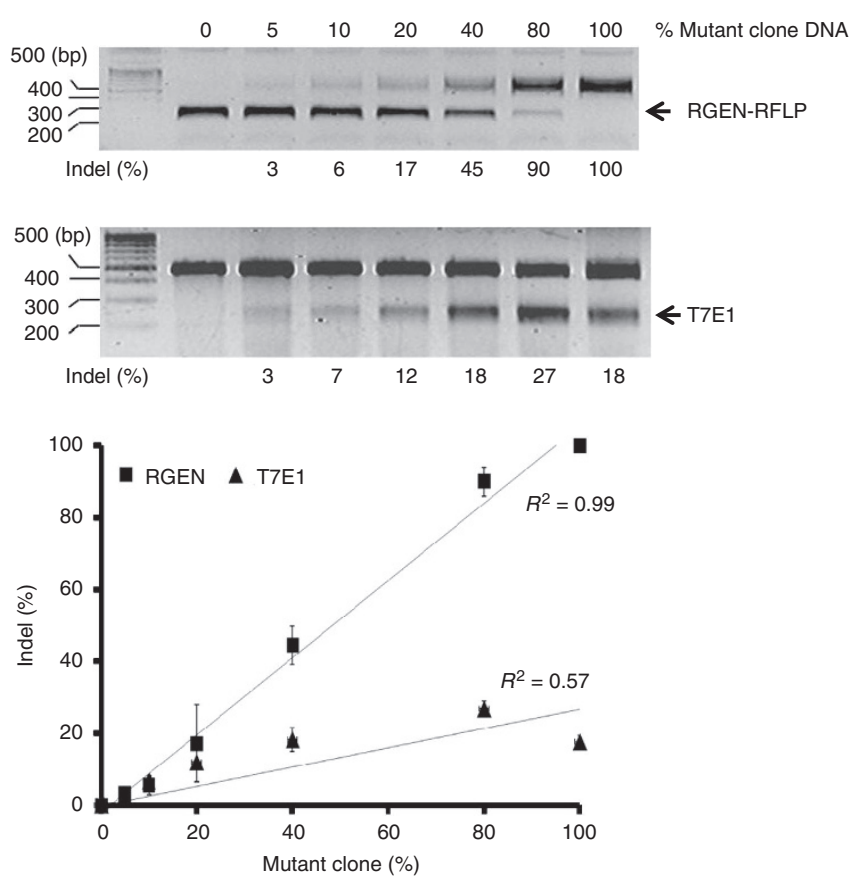

Figure 3 